\title{
The Corrosion and Passivity of Sputtered
Mg-Ti Alloys
}

\author{
Guang-Ling Song ${ }^{*}, 1,2,3$ \\ ${ }^{1}$ College of Materials, Xiamen University \\ ${ }^{2}$ State Key Laboratory of Physical Chemistry of Solid Surface, Department of Chemistry, \\ College of chemistry and Chemical Engineering, Xiamen University \\ ${ }^{3}$ Southern Center for Marine Materials Corrosion and Protection, Xiamen University \\ 422 S. Siming Rd., Xiamen 361005, PR. China \\ *guangling.song@ hotmail.com, glsong@xmu.edu.cn, +86-592-218-6802 \\ Kinga A. Unocic, Harry Meyer III, Ercan Cakmak, Michael P. Brady \\ Oak Ridge National Laboratory \\ 1 Bethel Valley Road, Oak Ridge, TN 37831 \\ Paul E. Gannon, Phil Himmer, Quinn Andrews \\ Montana State University \\ Bozeman, MT 59717
}

\begin{abstract}
This study explored the possibility of forming a "stainless" Mg-Ti alloy. The electrochemical behavior of magnetron-sputtered $\mathrm{Mg}$-Ti alloys was measured in a $\mathrm{NaCl}$ solution, and the surface films on the alloys were examined by XPS, SEM and TEM. Increased corrosion resistance was observed with increased $\mathrm{Ti}$ content in the sputtered Mg-Ti alloys, but passive-like behavior was not reached until the Ti level (atomic \%) was higher than the Mg level. The surface film that formed on sputtered $\mathrm{Mg}$-Ti based alloys in $\mathrm{NaCl}$ solution was thick, discontinuous and nonprotective, whereas a thin, continuous and protective $\mathrm{Mg}$ and $\mathrm{Ti}$ oxide film was formed on a sputtered Ti-Mg based alloy.
\end{abstract}

Keywords: A. Mg alloy; C. passivity; B. SEM; B. XPS; B.TEM

\#All the experiments were carried out at Oak Ridge National Laboratory. 


\section{Introduction}

Mg alloys have found potential applications in the medical [1-3] and auto [4-6] industries. Many commercial $\mathrm{Mg}$ alloys contain intermetallic phases that are anodic to the alloy matrices, and the presence of these intermetallics is believed to be detrimental to the corrosion resistance of the alloys in many cases [1-9]. The poor corrosion performance of $\mathrm{Mg}$ alloys is currently limiting their industrial applications [10], and great efforts have been made to improve their corrosion resistance [11-29]. Unfortunately, due to the high chemical activity of $\mathrm{Mg}$ and the limited solubility of beneficial alloying elements in $\mathrm{Mg}$, none of the studied alloys has shown adequate corrosion resistance thus far [30-34].Consequently, surface treatments and/or coatings are often needed for $\mathrm{Mg}$ alloys in practical applications [35-39].

Since a passivated metal can resist severe corrosion attack, it is of great interest to learn whether a "stainless" Mg alloy, like a Fe-base stainless steel, can be obtained through alloying Mg with strong passivating elements, such as $\mathrm{Cr}$, Ti, Aland/or Ni. Alloying changes not only the matrix composition, but also the amount and distribution of the intermetallic phases. In $\mathrm{Mg}$ alloys, the matrix phase is the most critical constituent, as it is always a constituent that is most susceptible to corrosion attack and selectively dissolved, while the secondary phases and other intermetallics are intact [9].Thus, the first step to a "stainless" $\mathrm{Mg}$ alloy is to obtain a passivated $\mathrm{Mg}$ matrix phase through alloying $\mathrm{Mg}$ with strong passivating elements.

It is well known that Fe needs to alloy with at least $\sim 12 \mathrm{wt} . \% \mathrm{Cr}$ to become passive [40]. $\mathrm{Mg}$ is 
much more active than $\mathrm{Fe}$. The minimum amounts of passivating elements required for $\mathrm{Mg}$ to become passive should be even higher. However, most of the strong passivating elements have very limited solid solubility in $\mathrm{Mg}$. For example, the solid solubility of $\mathrm{Al}$ in $\mathrm{Mg}$ is less than 9 wt.\% and that of $\mathrm{Ni}$ is only a few ppm by weight $[41,42]$. Chromium and Titanium cannot even be dissolved in $\mathrm{Mg}$ under equilibrium conditions. Therefore, the Mg matrix cannot be easily alloyed by these strong passivating elements through a traditional alloying process. Nonequilibrium approaches, such as rapid solidification, could be an option to form a passivated $\mathrm{Mg}$ matrix phase(a metastable alloy). Among those non-traditional metallurgic methods[43-46], magnetron sputtering can produce single-phase, non-equilibrium Mg alloys in a wide composition range. It can thus be used to fabricate single-phase $\mathrm{Mg}$-passivating element alloys to simulate the $\mathrm{Mg}$ matrices for studying the corrosion and passivation of $\mathrm{Mg}$ alloys.

There have beensomeinvestigations into the passivity of $\mathrm{Mg}$ alloys containing $\mathrm{Ni}, \mathrm{Y}, \mathrm{Nd}, \mathrm{Cr}, \mathrm{Al}$, Gd and Ti [33, 47-52]. For example, a distinct passive region has been detected in anodic polarization curves for amorphous $\mathrm{Mg}$ alloys containing $\mathrm{Ni}, \mathrm{Y}$ and $\mathrm{Nd}$ in a chloride-containing solution [47].However, it was concluded that alloying with Y and Gd did not significantly change the corrosion rate of $\mathrm{Mg}$ [33].It has been found that the corrosion performance deteriorates if the $\mathrm{Cr}$ concentration in the alloy is $2 \sim 8$ at. $\%$, but the corrosion resistance can be improved when the $\mathrm{Cr} /(\mathrm{Mg}+\mathrm{Cr})$ ratio by at.\% is higher than $1 / 3$, which permits enrichment of $\mathrm{Cr}$ in the surface film[48]. Up to $46 \mathrm{wt} . \%$ of Ti alloying has been reported to decrease the corrosion resistance of physcial vapor deposition (PVD) Mg alloys [49] . This detrimental effect of higher levels of Ti alloying has also been observed by Blawert et al. [50], whose magnetron-sputtered Mg-Ti alloys contain up to 56 wt.\% of Ti on Mg alloy and Si substrates. However, it should be 
noted that the PVD alloy layers usually contain pinholes, and the corrosive test solution can quickly penetrate though the alloy layer and reach the substrate. If the substrate is an electronically conducting material, electrochemical measurements would be significantly influenced by the substrate through the well-known galvanic effect, resulting in misleading corrosion results [51]. Moreover, the possibility cannot be excluded that the investigated Ti concentrations (<56 wt.\% or $<39$ at. \% ) in the PVD Mg alloys are too low to passivate $\mathrm{Mg}$. Therefore, the reported detrimental effect of Ti on corrosion resistance of PVD Mg-Ti alloys may not be a final conclusion. Further investigation is needed.

Among the candidate passivating elements, $\mathrm{Al}$ and $\mathrm{Ti}$ are of the greatest interest, because their addition to $\mathrm{Mg}$ in large amounts required to passivate $\mathrm{Mg}$ will not substantially increase the resultant alloy density. The Al alloying effect on corrosion has been extensively studied $[11,30]$. However, compared with the extensive research on $\mathrm{Al}$ alloying, there are far fewer investigations on the effect of Ti alloying additions on $\mathrm{Mg}$ corrosion. In fact, $\mathrm{Ti}$ is not only a light metal, but also a biocompatible element. Mg-Ti alloys may therefore potentially be used for light-weight structural parts and also for biodegradable implants [53,54].

In this study, to eliminate the influence of second phases and the effects of pin-holes in the deposited Mg-Ti alloys, the corrosion and passivation processes of magnetron-sputtered singlephase Mg-Ti alloys containing up to 51 at.\% Ti on an inert quartz substrate were investigated. The aim of this study was to explore the possibility of forming a passive $\mathrm{Mg}$ alloy through 
alloying with $\mathrm{Ti}$ in order to provide further insight into whether a stainless $\mathrm{Mg}$ alloy is achievable.

\section{Experimental}

\subsection{Mg-Ti alloy preparation}

Mg-Ti alloys were deposited on $1 \mathrm{~mm}$ thick25x $25 \mathrm{~cm}$ square quartz plates via RF magnetron sputtering using a load locked system with high-purity sputter targets (99.95 wt.\% Mg and 99.99 wt.\% Ti). Deposition was performed in 5 mTorr atmosphere which was controlled using a VAT pressure gate valve through flowing $100 \mathrm{sccm}$ of high-purity Ar (99.999 vol.\%). The ultimate base pressure was 0.3 mTorr with vacuum created using scroll and cryogenic pumping. Typical deposition time was $\sim 1.5 \mathrm{~h}$ resulting in a minimum $\sim 2 \mu \mathrm{m}$ thick deposited Mg-Ti layer; times were adjusted to accommodate limits in RF power for deposited Mg-Ti layers with high Ti content. A stainless steel frame was used to secure the quartz plates to the substrate platen, permitting each quartz plate equal area exposed to the $\mathrm{Mg} / \mathrm{Ti}$ vapor deposition. The substrate platen fixture was rotated at a constant speed $(\sim 30 \mathrm{rpm})$ during sputtering to promote deposition uniformity across all the quartz plates. The alloy composition was controlled by the specific charging powers applied to the $\mathrm{Mg}$ and Ti targets. By changing the powers, Mg-Ti alloy layers with different $\mathrm{Ti}$ and $\mathrm{Mg}$ contents were obtained.

\subsection{XRD analysis}


The X-ray diffraction (XRD) scans were performed on a PA Nalytical X'pert diffractometer using $\mathrm{CuK} \alpha$ radiation $(\lambda=1.540598 \AA$ ) with a grazing incidence setup wherein the $\mathrm{x}$-ray beam was held constant at $0.5^{\circ}$ angle of incidence as the detector was moved through the $2 \theta$ range. This setup was used in an effort to obtain proportionally more signal from the sputtered alloy films over the quartz substrate by minimizing the x-ray penetration depth. For these measurements, a parabolic x-ray mirror and a $0.09^{\circ}$ radial divergence limiting slit coupled with a proportional detector were used to achieve parallel beam optics. A $1 / 2^{\circ}$ anti-scatter slit and 0.04 rad. soller slits were also used in this setup.

\subsection{XPS Characterization}

X-ray photoelectron spectroscopy (XPS) analysis was conducted using a Thermo Scientific Model K-Alpha XPS instrument. The analysis used a monochromated, micro-focusing, Al K $\alpha$ $\mathrm{X}$-ray source $(1486.6 \mathrm{eV})$ with a $\sim 400 \mu \mathrm{m} \mathrm{X}$-ray spot size for maximum signal to obtain an average surface composition over the largest possible area. Survey spectra $(0-1350 \mathrm{eV})$ were acquired for qualitative and quantitative analyses, and high-resolution spectra were acquired for chemical state characterization of appropriate elements. All spectra were acquired with the charge neutralization flood gun turned on to maintain stable analysis conditions on the nominally insulating oxide sample surface. The typical pressure in the analysis chamber with the flood gun operating was $2 \times 10^{-7}$ mbar. Data were collected and processed using the Thermo Scientific Avantage XPS software package (v.4.61). Peak fitting was performed using mixed Gaussian/Lorentzian peak shapes and a Shirley/Smart type background. The Mg-metal was identified by a distinct plasmon feature at $\sim 60.5 \mathrm{eV}$. Mg-hydroxide has a lower binding energy 
(BE) than Mg-metal ( 49.3 eV vs. $49.8 \mathrm{eV})$. Mg-oxide has a higher BE than either the hydroxide or the metal $(\sim 50.5 \mathrm{eV})$. These characteristics were used to fit $\mathrm{Mg} 2 \mathrm{p}$ data. Likewise, C 1s data were fitted to distinguish $\mathrm{C}$-carbonate from $\mathrm{C}-\mathrm{O}, \mathrm{C}-\mathrm{C}$ and $\mathrm{C}$-carbide. The $\mathrm{O}$ 1s spectra were also fitted typically with two peaks. Depth profiling analyses were conducted with a Thermo Scientific EX06 argon ion gun operated at $1000 \mathrm{eV}$ over a $2 \mathrm{~mm}$ x $4 \mathrm{~mm}$ area. Further details of the analysis methodology are available in reference [55].

\section{4. $\quad$ SEM/TEM examination}

Scanning electron microscopy (SEM) was performed on Mg-Ti alloy surfaces using Hitachi model S4800. Cross-section scanning/transmission electron microscopy (STEM/TEM) specimens were prepared via the focus ion beam (FIB) in-situ lift-out technique using a Hitachi NB5000 FIB-SEM. A W+C overlayer was deposited to protect film integrity during milling. The TEM was performed using a JEOL 2200FS-AC STEM 200kV probe corrected microscope (using CEOS $\mathrm{C}_{\mathrm{s}}$-Corrector) that has $0.7 \AA$ resolution in STEM mode equipped with field emission gun (FEG) and also with a Bruker X Flash ${ }^{\circledR} 6 \mid 30$ silicon drift detector (SDD) that has

excellent energy resolution and larger solid angle of a $30 \mathrm{~mm}^{2}$ active chip area. Further details of the analysis methodology are available in reference [55].

\subsection{Immersion test}

The magnetron-sputtered Mg-Ti alloys on quartz plates were immersed in $15 \mathrm{~mL}$ of saturated $\mathrm{Mg}(\mathrm{OH})_{2}+0.1$ wt. $\% \mathrm{NaCl}$ aqueous testing solution. After $5 \mathrm{~h}$, they were taken out and rinsed with 
distilled water.

\subsection{Electrochemical Characterization}

A special electrode set-up as shown in Figure 1 was employed in this study to evaluate the corrosion performance and passivity of magnetron-sputtered $\mathrm{Mg}$-Ti alloys on square quartz plates. The Mg-Ti alloy surface was covered by a specimen mask tape (Gamry Port Hole Electroplating Tape, 3M470), leaving a $1 \mathrm{~cm}^{2}$ round area exposed in the center of the specimen surface. One of the square specimen corners was unmasked to permit electrical connection. The Mg-Ti specimen was carefully positioned in an electrolyte cell as a working electrode; the exposed round surface area of this specimen was fully immersed, while the unmasked corner clipped by a crocodile clip was above the solution waterline.

Polarization curve measurements were conducted in an electrolyte cell containing $450 \mathrm{~mL}$ of the saturated $\mathrm{Mg}(\mathrm{OH})_{2}+0.1 \mathrm{wt}$.\% $\mathrm{NaCl}$ testing solution using an electrochemical measurement system (Parstat 4000, Princeton Applied Research). In the cell, a Saturated Calomel Electrode (SCE) was used as reference electrode. The auxiliary electrode was a platinum foil. Before polarization, the specially masked working electrode was held in the testing solution at its open circuit potential (OCP) for $0.5 \mathrm{~h}$ to reach a relatively steady state. Potentiodynamic polarization curve was measured at an anodic scanning rate of $0.1667 \mathrm{mV} / \mathrm{s}$.

\section{Results}




\subsection{Compositions of magnetron-sputtered Mg-Ti alloys}

The Mg-Ti alloy compositions and corresponding $\mathrm{Mg}$ and Ti target powers are summarized in Table 1. The compositions of the deposited alloys were estimated from XPS analysis, taking the values at approximately 1000-1500 s of sputtering to represent the alloy (Figure 2). For a simplified nomenclature, only the $\mathrm{Mg}$ and Ti levels are used to identify the alloy. Carbon and oxygen were also detected in all as-sputtered alloys, with the highest concentrations at the outer surface from the air-formed film (removed after $\sim 100-200$ s of sputter etching). The $\mathrm{Mg}$ and $\mathrm{Ti}$ contents therefore do not sum to 100 at $\%$, e.g. the unalloyed $\mathrm{Mg}$ control alloy is labeled as Mg93Ti0 (zero Ti), with the remaining 7 at.\% coming from C and O. Particularly for the highest Ti content alloy, Mg28Ti51, higher residual levels of $\mathrm{C}$ and $\mathrm{O}$ were detected, approximately 10 at.\% each (Table 1). However, it should be noted that XPS analysis of a nominally pure Ti metal sheet suggested that Ar-ion sputter profiling likely creates surface carbide and oxide as clean Ti getters some of the residual gas in the XPS analysis chamber. Therefore, the XPS analysis likely overestimates the amount of $\mathrm{O}$ and $\mathrm{C}$ impurities present in the sputtered Mg-Ti alloys. XPS BE analysis suggested that some of this C impurity was associated with carbide in the sputtered alloy film, rather than artifact. Given the high solubility of $\mathrm{O}$ in $\mathrm{Ti}$, these results suggest that the Mg28Ti51alloy is metallic $\mathrm{Ti}(\mathrm{Mg})$, but likely also contains minor amounts of intermixed Ti-C and Ti-O (may be present in metastable solid solution, as will be described, second phase precipitates were not evident in XRD or TEM). Smaller C and O impurity amounts were also evident by XPS in the other Mg-Ti alloys (Table 1).

Table 1. The dependence of the Mg-Ti alloy compositions on the stationary disk holder on the specific changing powers applied to $\mathrm{Mg}$ and $\mathrm{Ti}$ targets 


\begin{tabular}{|c|c|c|c|c|c|c|}
\hline $\begin{array}{c}\text { Sputtered } \\
\text { alloy name }\end{array}$ & $\begin{array}{c}\text { Mg } \\
\text { power }\end{array}$ & $\begin{array}{c}\text { Ti } \\
\text { Power }\end{array}$ & $\begin{array}{c}\text { Mg } \\
\text { (at.\%) }\end{array}$ & $\begin{array}{c}\text { Ti } \\
\text { (at.\%) }\end{array}$ & $\begin{array}{c}\text { O } \\
\text { (at.\%) }\end{array}$ & $\begin{array}{c}\text { C } \\
\text { (at.\%) }\end{array}$ \\
\hline Mg93Ti0 & $500 \mathrm{~W}$ & - & 93.4 & 0.0 & 3.8 & 2.8 \\
\hline Mg68Ti19 & $500 \mathrm{~W}$ & $500 \mathrm{~W}$ & 68.5 & 19.3 & 4.7 & 7.5 \\
\hline Mg52Ti38 & $250 \mathrm{~W}$ & $800 \mathrm{~W}$ & 52.3 & 38.0 & 3.3 & 6.4 \\
\hline Mg28Ti51 & 100W & $800 \mathrm{~W}$ & 28.3 & 51.4 & 9.9 & 10.4 \\
\hline
\end{tabular}

\subsection{Microstructure of magnetron-sputtered Mg-Ti alloys}

The magnetron-sputtered Mg-Ti alloys have a columnar structure (typical TEM cross-section images are shown in Figure 3). All the deposited alloys were a few micrometers thick, consisting of vertical columnar grains on the quartz plates.

\subsection{Crystallographic orientations of magnetron-sputtered Mg-Ti alloys}

The XRD patterns of the magnetron sputtered Mg93Ti0, Mg68Ti19, Mg52Ti38 and Mg28Ti51 alloys are presented in Figure 4. Strong preferred crystallographic orientations in Mg93Ti0, Mg68Ti19 and Mg52Ti38 were evident from the prominent $\mathrm{Mg}$ or $\mathrm{Mg}(\mathrm{Ti})(10 \overline{1} 3)$ reflection, with a minor (0002) peak observed only for the Mg93Ti0. These results suggest that a highly directional Mg-Ti alloy growth occurred with HCP (0002) and (1013) planes parallel to the substrate in Mg93Ti0, and(1013) planes parallel to the substrate inMg68Ti19 and Mg52Ti38.

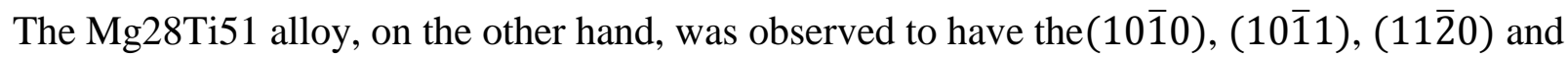
$(11 \overline{2} 2)$ crystallographic planes parallel to the substrate. As Ti content increased from 0 at.\% to 38 at.\%, the $(10 \overline{1} 3)$ peak shifted towards higher $2 \Theta$, i.e., lower d-spacing, which was a result of the smaller unit cell dimensions of Ti substituting for $\mathrm{Mg}$. Meanwhile, the $\operatorname{Mg}(0002)$ peak 
disappeared with increasing Ti content, indicating that the Ti alloying also, to some degree, altered the crystallographic growth orientation of the sputtered alloys. Moreover, when the Ti content was high enough, reaching 51 at.\%, the crystallographic lattice of Mg-Ti changed from $\mathrm{Mg}$ to $\mathrm{Ti}$, i.e. $\mathrm{Ti}(\mathrm{Mg})$, characterized by a different spectrum with(10 $\overline{1} 0),(10 \overline{1} 1),(11 \overline{2} 0)$ and (112̄2)peakspresent. In this case, the spectrum was similar to that reported for a Mg50Ti50 alloy, in which the $(11 \overline{2} 0)$ and $(11 \overline{2} 2)$ peaks were interpreted as characteristics of the Ti crystal structure [44]. Other than the various preferred crystallographic orientations presented in Figure 4, no other phase was detected from the measured XRD patterns. This indicates that the magnetron-sputtered $\mathrm{Mg}$-Ti thin layers on the quartz plates were primarily single-phase alloys (amorphous regions were also not apparent in the XRD data).

\subsection{Corrosion surface morphology}

The as magnetron-sputtered $\mathrm{Mg}$-Ti alloy surfaces were all initially mirror-like finishes on visual inspection. After immersion in the test solution for $5 \mathrm{~h}$, the Mg93Ti0 and Mg68Ti19 alloy surfaces darkened and the Mg52Ti38 alloy surface exhibited some black areas. In contrast, no visual changes were evident for the surface of the Mg28Ti51 alloy. The detailed surface SEM morphologies after immersion are shown in Figure 5. The corroded surface of the magnetronsputtered magnesium Mg93Ti0was uniform with many cracks (Figure 5 (a)). The addition of 19 at.\% Ti resulted in a non-uniform corroded surface for the Mg68Ti19(Figure 5(b)); the corroded dark areas were apparently randomly distributed over the alloy surface together with microcracks. Such surface cracking is frequently observed in MgO-base corrosion films, and has been attributed to factors such as Pilling-Bedworth ratio effects and/or dehydration of the aqueous- 
formed $\mathrm{MgO}$ film $[55,56]$. When the Ti content was increased to 38 at.\%, only some local surface areas were corroded and the remaining areas were intact on the Mg52Ti38alloy (Figure 5 (c)). Immersion corrosion did not lead to significant attack of the surface of the high Ti-content alloy Mg28Ti51, and only some tiny dark spots were observed on the surface after immersion by SEM((Figure 5 (d)). These morphologic observations (Figure 5) suggest that Mg93Ti0 and Mg68Ti19 were active alloys that can be rapidly corroded,Mg52Ti38 was a transitional alloy that may be locally corroded, and Mg28Ti51was a passive alloy that was not rapidly corroded under these conditions. In summary, the surface corrosion morphology observations suggested that the passivity of Mg-Ti alloy increased while the corrosion rate decreased as the Ti content was increased, with possible passive-like behavior achieved when the alloy becomes Ti based from an atomic percent perspective.

\subsection{Corrosion film cross-section}

After $5 \mathrm{~h}$ of immersion in the saturated $\mathrm{Mg}(\mathrm{OH})_{2}+0.1 \mathrm{wt} . \% \mathrm{NaCl}$ test solution, the magnetronsputtered Mg alloy Mg93Ti0 had a uniform but quite thick 0.3 0.4 $\mu \mathrm{m} \mathrm{MgO}$ based corrosion film (Figure 6 (a)), which may also contain some small amount of hydroxides (only MgO could be definitively fit from the XPS data).This film was relatively uniform, similar to that observed on ingot pure $\mathrm{Mg}$ [56], and much thicker than typical nanometer thick passive films formed on stainless steels, for example[57, 58]. Alloying with a small amount of Ti (e.g. Mg68Ti19) resulted in a non-uniform cross-section corrosion film (Figure 7(a)). The reaction product showed penetrations deep $(\sim$ several $\mu \mathrm{m})$ in some areas whilst the attack was very shallow in the other

areas (Figure 7(a) and (b)). A further increase in Ti concentration (e.g. Mg52Ti38 alloy) resulted 
in a transition to a thin surface film in the imaged section. Although this film was too thin to be clearly seen in the TEM cross-section image(Figure 8(a)), the O map (Figure 8(c)) suggested the existence of a thin oxide film on the alloy surface, which was confirmed by XPS data in Figure 9 (c). Cross-section TEM imaging of the Mg28Ti51 alloy after $5 \mathrm{~h}$ of immersion was not pursued due to the near-absence of corrosive attack in visual and SEM surface examination. Instead, after immersion, this specimen was characterized primarily by XPS (Fig 9d-details in the following section)

\subsection{Surface composition after corrosion}

The magnetron-sputtered Mg-Ti alloy surface compositions after $5 \mathrm{~h}$ of immersion in saturated $\mathrm{Mg}(\mathrm{OH})_{2}+0.1$ wt. $\% \mathrm{NaCl}$ were determined by XPS and are shown in Figure 9 and Table 2.For all alloys a minor amount (a few at.\%) of hydrocarbon and carbonate bonding were detected at the outer surface, both as-deposited and after $5 \mathrm{~h}$ immersion (Table 2). Figure 9 (a) shows the element distributions vs. depth in the Mg93Ti0 alloy by XPS. High levels of O were maintained out to 1300s of sputter etching, indicating extensive corrosion of the Mg93Ti0 alloy. Due to $\mathrm{O}$ sputter artifacts, $\mathrm{MgO}$ and $\mathrm{Mg}(\mathrm{OH})_{2}$ cannot be definitively distinguished based on $\mathrm{Mg}$ and $\mathrm{O}$ content alone. However, based on XPS BE analysis, the film was primarily $\mathrm{MgO}$, with lesser amounts of $\mathrm{Mg}(\mathrm{OH})_{2}$ also possibly present at the film surface.

On Mg68Ti19, the O level had a sharp decrease after the first 100s of sputter etching, then it leveled off, but still stayed above 30 at.\% for the 1800s of sputter etching depth utilized (Figure 9 
(b)), consistent with the thick, non-uniform attack observed in the TEM section (Figure 6). The XPS BE analysis (Table 2) indicated that the film was primarily MgO-base, possibly with a minor amount of hydroxide. The Ti was observed in both oxide, metal, and carbide binding states in the near surface regions, at far lower oxidized levels than $\mathrm{Mg}$ (Table 2).In contrast, the XPS results obtained from the surface region in Mg52Ti38 (Figure 9(c)), indicated that the O level dropped below 10 at.\% in the first 100s, implying that the surface corrosion film at this location was very thin, consistent with the section imaged in TEM (Figure 8). The BE analysis was again consistent with an MgO-base film, with Ti also present and in both oxidized and metallic/carbide states. The $\mathrm{O}$ distribution in the high Ti-containing Mg-Ti alloy Mg28Ti51also decreased rapidly with depth, down to 20 at.\% in the first 150s (Figure 9 (d)), and approached 10 at.\% O level at $500 \mathrm{~s}$, similar to that observed in the as-deposited alloy surface (Figure 2(d)). This indicates that the corrosion film formed on the Mg28Ti51 alloys was also quite thin and protective. The XPS BE analysis (Table 2) suggested the reaction product was similar to the film observed on the thin corrosion film surface regions of Mg52Ti38, which was MgO based, and $\mathrm{Ti}$ presented in both oxidized and metal/carbide states. Furthermore, consistent with the Ti-rich alloy composition (e.g. Mg28Ti51), the oxidized and metal Ti fraction in the near surface region (45 s sputtering in Table 2) was higher than the corresponding Mg fractions. This observation suggests that Ti enrichment relative to the Mg occurred in the surface film during immersion, which may be responsible for the improved corrosion resistance of $\mathrm{Mg}$ by $\mathrm{Ti}$ alloying when the Ti level exceeded the Mg level.

Table 2.Estimated phase fraction/bonding type in at. \% after $45 \mathrm{~s}$ and $800 \mathrm{~s}$ of sputtering based on BE fitting of Figure 9 XPS data for alloy surfaces after $5 \mathrm{~h}$ of immersion in 
saturated $\mathrm{Mg}(\mathrm{OH})_{2}+0.1 \mathrm{wt} . \% \mathrm{NaCl}$. Due to the complexity of the BE fitting for corroded Mg-Ti surfaces, the estimated phase fractions should be considered semi-quantitative.

\begin{tabular}{|c|c|c|c|c|c|c|c|c|}
\hline $\begin{array}{l}\text { Alloy/Sputter } \\
\text { depth (seconds) }\end{array}$ & C-C & $\mathrm{CO}_{3}$ & $\begin{array}{l}* \mathrm{C}- \\
\text { carbide }\end{array}$ & $\begin{array}{l}\text { O- } \\
\text { Total }\end{array}$ & $\begin{array}{l}\text { Ti } \\
\text { Metal }\end{array}$ & $\begin{array}{l}\text { Ti } \\
\text { Oxidize } \\
\text { d }\end{array}$ & $\begin{array}{l}\text { Mg } \\
\text { Metal }\end{array}$ & $\begin{array}{l}* * \mathrm{Mg} \\
\text { Oxidize } \\
\text { d }\end{array}$ \\
\hline Mg93Ti0/45s & 3.1 & 3.2 & 0 & 44.4 & 0 & 0 & 12.4 & 36.9 \\
\hline Mg93Ti0/800s & 2 & 1 & 0 & 16.6 & 0 & 0 & 63 & 17.4 \\
\hline Mg68Ti19/45s & 1.6 & 0.4 & 1.3 & 43.6 & 2.5 & 6.6 & 4.1 & 39.9 \\
\hline Mg68Ti19/800s & 0.7 & 0.6 & 1.9 & 36.7 & 10.1 & 2.2 & 14.6 & 33.1 \\
\hline Mg52Ti38/45s & 0.8 & 0.7 & 2.8 & 22.1 & 18 & 9.4 & 36.2 & 10 \\
\hline Mg52Ti38/800s & 0.3 & 0.3 & 3.8 & 1.6 & 37.3 & 1.4 & 53.2 & 2.1 \\
\hline Mg28Ti51/45s & 4 & 0.7 & 2.4 & 41.8 & 12.4 & 20.9 & 6 & 11.8 \\
\hline Mg28Ti51/800s & 1.4 & 0.6 & 7.1 & 11.5 & 46.7 & 3.4 & 25.6 & 3.1 \\
\hline
\end{tabular}

*estimated to be primarily Ti-C

**estimated to be primarily $\mathrm{MgO}$, may also contain minor amounts of $\mathrm{Mg}(\mathrm{OH})_{2}$

\subsection{Polarization behavior}

Figure 10 shows the polarization curves of the magnetron-sputtered $\mathrm{Mg}$-Ti alloys in saturated $\mathrm{Mg}(\mathrm{OH})_{2}+0.1$ wt \% $\mathrm{NaCl}$ solution. The sputtered unalloyed $\mathrm{Mg}$ control, $\mathrm{Mg} 93 \mathrm{Ti}$, had an open-circuit potential further negative than $-1.8 \mathrm{~V}$ and high anodic current densities. This means that this sample was being actively corroded in the test solution. The addition of $\mathrm{Ti}$ into $\mathrm{Mg}$ positively shifted the open-circuit potential and reduced the anodic current densities. For example, all theMg68Ti19, Mg52Ti38 and Mg28Ti51 alloys had reduced anodic current densities compared withMg93Ti0, and the reduction became larger with increasing Ti content. The anodic current densities of the Ti-based alloy Mg28Ti51were lower than those of Mg93Ti0, which means that the former alloy had better passivity. Mg52Ti38 only showed a passivating tendency in a narrow anodic region (about $100 \mathrm{mV}$ more positive than the open-circuit potential), 
beyond which (pointed by the arrow in the figure)the passivity broke down and a large increase in current density occurred. Thus, this alloy could be in a transitional state; it may have originally been in a passive state, but a small fluctuation or stimulation could have moved it to an active state. Although Mg68Ti19had a much more positive open-circuit potential than Mg93Ti0, its anodic current density also increased dramatically when it was slightly anodically polarized. In other words, the alloy was very active at its open-circuit potential. Thus, Mg68Ti19 was also an active alloy like Mg93Ti0. These electrochemical characteristics (Figure 10) match very well the corrosion morphology observations under SEM (Figure 5) and TEM from the immersion exposures (Figure 6-Figure 8).

\section{Discussion}

Titanium is more stable than $\mathrm{Mg}$ in salt solutions, and itself is a strong passivating element. An active metal after alloying with $\mathrm{Ti}$ is normally expected to have a decreased corrosion rate. In this study, Ti alloying did inhibit the anodic dissolution of $\mathrm{Mg}$ (see Figure 10). This is likely because 1) the presence of $\mathrm{Ti}$ in the $\mathrm{Mg}$-Ti alloy may stabilize the substrate metal under the surface film, and 2) the oxidized $\mathrm{Ti}$ in the surface film may improve the passivity and reduce film dissolution.

Apart from the expected reduction in anodic current densities with increasing Ti content, there was an interesting observation from the polarization curve measurements (Figure 10); the cathodic current densities increased first and then decreased as the Ti content in the Mg-Ti alloy 
increased. This cannot be explained by Ti's stabilizing effect or its strong passivating ability alone. To understand this cathodic behavior, the influence of Ti alloying on Mg crystal texture should be considered. It has been reported that the grains in magnetron-sputtered Mg have their close-packed basal atomic planes mainly parallel to the sputtering substrate, and more and more prismatic planes appears the Ti addition increases[44]. This is also verified in the current study. The basal planes parallel to the substrate were detected in Mg93Ti0, but they disappeared in alloys Mg68Ti19 and Mg52Ti28 (Figure 4). In the two alloys with relatively higher Ti contents, prismatic plane (1013) became the only detectable peak in their XRD spectra. When the Ti content was higher than the $\mathrm{Mg}$, more vertical planes such as (1010) and (112̄0)began to appear and the Mg hcp crystal structure turned into the Ti hcp structure. It is well known that the densely packed basal plane has a higher atomic coordination and tighter atomic bond, and thus it is more stable than loosely packed prismatic planes[59,60].It is speculated that the active prismatic planes may activate the cathodic hydrogen evolution before they are passivated. Therefore, there could be two contradictory factors influencing the cathodic behavior of Mg-Ti alloys: 1) the Ti concentration, and 2) the grain orientation. In the magnetron-sputtered $\mathrm{Mg}$, the relatively stable basal planes dominate its surface. Hence, the cathodic reaction was not as active on the surface. When the Ti content was too low to passivate the alloy surface but increased the number of prismatic planes at the surface, the cathodic reaction could be facilitated by the active prismatic planes exposed on the surface, resulting in higher cathodic current densities. After a large amount of Ti was added, the prismatic planes could be covered by a stable passive film and lose their activity. In this case, the cathodic reaction on the surface will become difficult again. 
A monotonic decrease in anodic current densities with increasing Ti content in the alloy coupled with a non-monotonic increase in cathodic current densities (the cathodic current densities increased with Ti content at low contents and then decreased with Ti content at high certain Ti concentrations) can lead to a slightly worsened corrosion performance for the alloy with a low $\mathrm{Ti}$ content. This potentially explains the phenomenon reported by Mitchell et al. [49] that the corrosion resistance of Mg-Ti alloys with up to $46 \mathrm{wt} . \% \mathrm{Ti}$ was inferior to that of PVD Mg. This study also confirmed that $56 \mathrm{wt} . \%$ (39 at.\%) Ti addition to $\mathrm{Mg}$ is not enough to fully passivate $\mathrm{Mg}$ as reported previously [50].

\section{Implications}

This study demonstrated that passivity can be achieved for a magnetron-sputtered single phase Mg-Ti alloy, but only when the Ti content in the metastable solid solution is higher than 51 at.\%. In this case, the alloy is actually Ti based. Surface alloying may passivate a Mg alloy without significantly altering its bulk composition and properties [61]. Therefore, it might be possible for a Mg alloy to have a surface layer containing a large amount of Ti to form a continuous, stable and protective passive film. There are several processes that may result in such an alloyed Mg surface. For example, a strong passivating element (e.g. Cr or Ti) can get into a Mg alloy surface through ion-implantation $[62,63]$. Surface alloying with strong passivating elements may be an effective way to solve the corrosion problem of Mg alloys in future practical applications. 


\section{Conclusions}

1. When Mg was alloyed with Tito form a primarily single-phase Mg-Ti alloy through a non-equilibrium magnetron-sputtering process, its passivity increased with increased Ti concentration. Titanium alloying reduced the anodic dissolution rate of Mg. Complete passivity was achieved only after the Ti content was increased to the point where the Mg-Ti alloy became Ti based.

2. Due to the complicated cathodic polarization behavior, the corrosion rate did not monotonically decrease with increased Ti content. The increased cathodic current densities with small Ti additions due to the thinning of the surface film may lead to a slightly higher corrosion current density and thus worsened the corrosion performance.

3. Formation of a continuous thin protective surface film was responsible for the establishment of the alloy passivity. Such a passive film can only be formed on a Ti-based Mg-Ti alloy with a Ti crystal structure. On a low Ti-containing alloy with the Mg crystal structure, the surface film was thick but not protective. When the Ti content was not high enough, a thin film formed on some local surface areas, while on the other areas the film was a thick non-protective corrosion product layer.

4. The surface film on $\mathrm{Mg}-\mathrm{Ti}$ alloy consisted of $\mathrm{Mg}$ and Ti oxides. The ratio of $\mathrm{Ti}$ oxides to Mg oxides increased when the Ti content in the substrate alloy was increased. 


\section{Acknowledgements:}

The authors thank D.W. Coffey, T.M. Lowe, and T. Jordan for their assistance with the experimental work. The authors also thank J. Qu, J.K. Thomson, and B.A. Pint for providing useful comments and discussions. It is acknowledged that the National Environmental Corrosion Platform of China provided support in revising this paper.

This research was sponsored by the U.S. DOE EERE Vehicle Technologies Office. This manuscript has been authored by UT-Battelle, LLC under Contract No. DE-AC05-00OR22725 with the U.S. Department of Energy. The United States Government retains and the publisher, by accepting the article for publication, acknowledges that the United States Government retains a non-exclusive, paid-up, irrevocable, world-wide license to publish or reproduce the published form of this manuscript, or allow others to do so, for United States Government purposes. The Department of Energy will provide public access to these results of federally sponsored research in accordance with the DOE Public Access Plan (http://energy.gov/downloads/doe-publicaccess-plan). 
List of Figures:

Figure 1. Schematic illustration of the Mg-Ti electrode and electrolyte cell set-up for polarization curve measurement

Figure 2. XPS element profiles of as-magnetron-sputtered Mg-Ti alloys: (a) Mg93Ti0, (b) Mg68Ti19, (c) Mg52Ti38 and (d) Mg28Ti51

Figure 3. Bright Field STEM images of typical cross-sections of magnetron-sputtered MgTi alloys: (a) Mg93Ti0 and (b) Mg52Ti38

Figure 4. XRD spectra of magnetron-sputtered Mg-Ti alloys

Figure 5.Backscattered SEM images of the top view of magnetron-sputtered Ti-Mg alloys: (a) Mg93Ti0, (b) Mg68Ti19, (c) Mg52Ti38 and (d) Mg28Ti51, after $5 \mathrm{~h}$ of immersion in saturated $\mathrm{Mg}(\mathrm{OH})_{2}+0.1$ wt. $\% \mathrm{NaCl}$.

Figure 6.Bright Field STEM image (a) of the cross-section for the magnetron-sputtered Mg-Ti alloy Mg93Ti0 after $5 \mathrm{~h}$ of immersion in saturated $\mathrm{Mg}(\mathrm{OH})_{2}+0.1 \mathrm{wt} . \% \mathrm{NaCl}$, and EDS elemental maps for $\mathrm{Mg}(\mathrm{b})$ and $\mathrm{O}(\mathrm{c})$.

Figure 7.Bight Field STEM images $(a, b)$ of the cross-section for the magnetron-sputtered Mg68Ti19 alloy after $5 \mathrm{~h}$ of immersion in saturated $\mathrm{Mg}(\mathrm{OH})_{2}+0.1 \mathrm{wt} . \% \mathrm{NaCl}$, and $\mathrm{EDS}$ elemental maps for $\mathrm{Mg}(\mathrm{c}), \mathrm{O}(\mathrm{d})$, and Ti (e).

Figure 8. Bright Field STEM image (a) of the cross-section of the magnetron-sputtered Mg-Ti alloy Mg52Ti38 after $5 \mathrm{~h}$ of immersion in saturated $\mathrm{Mg}(\mathrm{OH}) 2+0.1 \mathrm{wt} . \% \mathrm{NaCl}$, and EDS elemental maps for $\mathrm{Mg}(\mathrm{b}), \mathrm{O}$ (c), and Ti (d).

Figure 9.XPS element profiles of Mg-Ti alloys: (a) Mg93Ti0, (b) Mg68Ti19, (c) Mg52Ti38 and (d) Mg28Ti51after $5 \mathrm{~h}$ of immersion in saturated $\mathrm{Mg}(\mathrm{OH})_{2}+0.1 \mathrm{wt} . \% \mathrm{NaCl}$.

Figure 10. Polarization curves for magnetron-sputtered Mg-Ti alloys in the saturated $\mathrm{Mg}(\mathrm{OH})_{2}+0.1$ wt. $\% \mathrm{NaCl}$ solution (The arrow points the passivity breakdown on the curve) 


\section{References}

1. J.Vormann, Magnesium: nutrition and metabolism, Molecular Aspects of Medicine, 24(2003) 27-37

2. Z. Li, G.-L. Song, S. Song, Effect of Bicarbonate on Biodegradation behaviour of pure magnesium in a simulated body fluid, Electrochimica Acta 115 (2014) 56-65

3. G.-L. Song, R.-C. Zeng, Preface for the special issue on light metals as biomaterials, Frontiers of Materials Science, 8(3) (2014)199-199

4. G.L.Marka and J.Kruger, Corrosion of magnesium, International Materials Reviews 38(3) 138-153

5. E. Ghali, Magnesium and magnesium alloys, Uhlig's Corrosion Handbook (2000) 793-830.

6. P.E. Krajewski, S. Kim, J.T. Carter, R. Verma, Magnesium sheet: automotive applications and future opportunities, Korean Institute of Metals and Materials: Trends in Metals and Materials Engineering 20 (2007) 60-68.

7. A. Pardo, M.C. Merino, A.E. Coy, R. Arrabal, F. Viejo, E. Matykina, Corrosion behaviour of magnesium/aluminium alloys in 3.5 wt.\% NaCl, Corrosion Science 50 (2008) 823-834.

8. G.-L. Song, Z.Xu, Effect of Microstructure evolution on corrosion of different crystal surfaces of AZ31 Mg alloy in a chloride containing solution, Corrosion Science 54 (2012) 97-105

9. G. Song, Recent progress in corrosion and protection of magnesium alloys, Advanced Engineering Materials 7(2005)563-586

10. B.A.Shaw, Corrosion Resistance of Magnesium Alloys, ASM Handbook, Volume 13A Corrosion: Fundamentals, Testing, and Protection, 2003 ASM International, p692-696

11. G.-L. Song (ed.), Corrosion of Mg alloys, WP publishing, Pastow, UK (2011)

12. G.-L. Song (ed.), Corrosion Prevention of Mg alloys, WP publishing, Pastow, UK (2013)

13 . J.E.Gary, B.Luan, Protective coatings on magnesium and its alloys-a critical review, Journal of alloys and compounds, 336(2002);88-113

14. X.Zhu, H.G.Yang, M.K.Lei, Corrosion resistance of Al ion implanted AZ31 magnesium alloy at elevated temperature, Surface \& Coatings Technology 201(2007)6663-6666

15. N.Koura, H.Nagase, A.Sato, S.Kumakura, K.Takeuchi, K.Ui, T.Tsuda, C.Loong, Electroless plating of aluminium from a room-temperature ionic liquid electrolyte, Journal of The Electrochemical Society 155(2) (2008) D155-D157

16. M. Yamasaki, N. Hayashi, S. Izumi, Y. Kawamura, Corrosion behavior of rapidly solidified $\mathrm{Mg}-\mathrm{Zn}$-rare earth element alloys in $\mathrm{NaCl}$ solution, Corrosion Science 49 (2007) 255-262.

17. G. Baril, N. Pébère, The corrosion of pure magnesium in aerated and deaerated sodium sulphate solutions, Corrosion Science 43 (2001) 471-484.

18. S. Budruk Abhijeet, R. Balasubramaniam, M. Gupta, Corrosion behaviour of $\mathrm{Mg}-\mathrm{Cu}$ and Mg-Mo composites in 3.5\% NaCl, Corrosion Science 50 (2008) 2423-2428.

19. A.A. El-Moneim, E. Akiyama, K.M. Ismail, K. Hashimoto, Corrosion behaviour of sputterdeposited Mg-Zr alloys in a borate buffer solution, Corrosion Science 53 (2011) 2988-2993.

20. A.A. El-Moneim, E. Akiyama, K.M. Ismail, K. Hashimoto, Corrosion behaviour of sputterdeposited Mg-Zr alloys in a borate buffer solution, Corrosion Science 53 (2011) 2988-2993.

21. D.S. Gandel, M.A. Easton, M.A. Gibson, T. Abbott, N. Birbilis, The influence of zirconium additions on the corrosion of magnesium, Corrosion Science 81 (2014) 27-35 
22. S. Izumi, M. Yamasaki, Y. Kawamura, Relation between corrosion behavior and microstructure of $\mathrm{Mg}-\mathrm{Zn}-\mathrm{Y}$ alloys prepared by rapid solidification at various cooling rates, Corrosion Science, 51 (2009) 395-402

23. J. Liao, M. Hotta, N. Yamamoto, Corrosion behavior of fine-grained AZ31B magnesium alloy, Corrosion Science 61 (2012) 208-214.

24. V. Lisitsyn, G. Ben-Hamu, D. Eliezer, K.S. Shin, The role of Ca microalloying on the microstructure and corrosion behavior of $\mathrm{Mg}-6 \mathrm{Zn}-\mathrm{Mn}-(0.5-2) \mathrm{Si}$ alloys, Corrosion Science 51 (2009) 776-784

25. H. Matsubara, Y. Ichige, K. Fujita, H. Nishiyama, K. Hodouchi, Effect of impurity Fe on corrosion behavior of AM50 and AM60 magnesium alloys, Corrosion Science 66 (2013) 203-210

26. F. Mert, C. Blawert, K.U. Kainer, N. Hort, Influence of cerium additions on the corrosion behaviour of high pressure die cast AM50 alloy, Corrosion Science 65 (2012) 145-151.

27. W.C. Neil, M. Forsyth, P.C. Howlett, C.R. Hutchinson, B.R.W. Hinton, Corrosion of heat treated magnesium alloy ZE41, Corrosion Science 53 (2011) 3299-3308.

28. P. Pérez, E. Onofre, S. Cabeza, I. Llorente, J.A. del Valle, M.C. García-Alonso, P. Adeva, M.L. Escudero, Corrosion behaviour of $\mathrm{Mg}-\mathrm{Zn}-\mathrm{Y}-$ Mischmetal alloys in phosphate buffer saline solution, Corrosion Science 69 (2013) 226-235.

29. W. Zhou, T. Shen, N.N. Aung, Effect of heat treatment on corrosion behaviour of magnesium alloy AZ91D in simulated body fluid, Corrosion Science 52 (2010) 1035-1041.

30. A.Atrens, G.-L. Song, M. Liu, Z. Shi, F. Cao, M. S. Dargusch, Review of recent developments in the field of magnesium corrosion, Advanced Engineering Materials (2015) DOI: $10.1002 /$ adem.201400434

31. G.-L. Song, M. Liu, The effect of surface pretreatment on the corrosion performance of electroless E-coating coated AZ31, Corrosion Science 62 (2012) 61-72.

32. X.Gu, Y.Zheng, Y.Cheng,S.Zhong,T.Xi, In vitro corrosion and biocompatibility of binary magnesium alloys. Biomaterials 30 (2009) 484-498.

33. K.Schluter, Z.Shi, C.Zamponi, F.Cao, E.Quandt, A.Atrens, Corrosion performance and mechanical properties of sputter-deposited $\mathrm{MgY}$ and MgGd alloys, Corrosion Science 78(2014)43-54

34. H.Elsentriecy, H.Luo, H.Meyer, L.Grado, J.Qu, Effects of pretreatment and process temperature of a conversion coating produced by an aprotic ammonium-phosphate ionic liquid on magnesium corrosion protection, Electrochimica Acta 123(2014)58-65

35. R.Arrabal, E.Matykina, F.Viejo, P.Skeldon, G.E.Thompson, Corrosion resistance of WE43 and AZ91D magnesium alloys with phosphate PEO coatings, Corrosion Science 50(2008)1744-1752

36. T.S.Lim, H.S Tyu, S-H.Hong, Electrochemical corrosion properties of $\mathrm{CeO}_{2}$-containing coatings on AZ31 magnesium alloys prepared by plasma electrolytic oxidation, Corrosion Science 62(2012)104-111

37. R.-G. Hu, S. Zhang, J.-F.Bu, C.-J.Lin, G.-L. Song, Recent progress in corrosion protection of magnesium alloys by organic coatings, Progress in Organic Coatings, 73(2012)129-141

38. G.-L. Song, N. Dudney, J. Li, R. Sacci, J. Thomson, The possibility of forming a sacrificial anode coating for Mg, Corrosion Science 87(2014)11-14

39. S. Song, G.-L.Song, W.Shen, M. Liu, Corrosion and electrochemical evaluation of coated magnesium alloys, Corrosion 68(2012)015005-1-11 
40. M. Blair, Corrosion of Cast Stainless Steels, Corrosion: Materials, Vol 13B, ASM Handbook, ASM International, 2005, p78-87

41. Al (Aluminum) Binary Alloy Phase Diagrams, Alloy Phase Diagrams, Vol 3, in ASM Handbook, ASM International, 1992, p 2.4-2.56

42. Mg (Magnesium) Binary Alloy Phase Diagrams, Alloy Phase Diagrams, Vol 3, in ASM Handbook, ASM International, 1992, p 2.280-2.285

43. C.H. Olk, D.B. Haddad, Growth and structure of a combinatorial array of mixed-phase magnesium-aluminum thin-film alloys, Applied Physics A: Materials Science and Processing 88/2 (2007) 249-253

44. G.-L. Song, D. Haddad, The grains and topographies of magnetron sputter-deposited Mg-Ti alloy thin films, Materials Chemistry and Physics 125 (2010) 548-552

45. K.R. Baldwin, D.J. Bray, G.D. Howard, R.W. Gardiner, Corrosion behavior of some vapordeposited magnesium alloys,Materials Science and Technology 12/11 (1996) 937-943.

46. S. Rousselot, M.P. Bichat, D. Guay, L. Roue, Structure and electrochemical behaviour of metastable Mg50Ti50alloy prepared by ball milling, Journal of Power Sources 175/1 (2008) 621-624.

47. Y H.ao, Y.Li, A.Wee, Corrosion behavior of melt-spun Mg65Ni20Nd15 and Mg65Cu25Y10 metallic glasses. Electrochimica Acta 48 (2003) 2641-2650.

48. M. Samulevičien, P. Miečinskas, K. Leinartas, A. Grigucevičien, P. Kalinauskas, V. Jasulaitien, R. Jušknas, E. Juzeliūnas, Corrosion resistance of nanocrystalline $\mathrm{Mg}-\mathrm{Cr}$ alloys deposited by magnetron sputtering, Materials Chemistry and Physics 126/3 (2011) 898-903.

49. T. Mitchell, S. Diplas, P. Tsakiropoulos, Characterisation of corrosion products formed on PVD in situ mechanically worked Mg-Ti alloys, Journal of Alloys and Compounds 392(2005) 127-141

50. C. Blawert, V. Heitmann, W.Dietzel, M. Störmer, Y. Bohne, S.Mändl, B. Rauschenbac, Corrosion properties of supersaturated magnesium alloy systems, Materials Science Forum 539 - 543 (2007)1679-1684

51. P.B.Srinivasan, C.Blawert, D.Hoche, Corrosion of innovative Magnesium (Mg) alloys, in G.-L.Song (ed.), Corrosion of Magnesium Alloys, WP publishing (2011), pp234-265

52. R. C. Wolfe, B. A. Shaw, The effect of thermal treatment on the corrosion properties of vapor deposited magnesium alloyed with yttrium, aluminum, titanium, and misch metal, Journal of Alloys and Compounds 437 (2007) 157-164

53. E. Zhang, L. Xu, K. Yang, Formation by ion plating of Ti-coating on pure Mg for biomedical applications, Scripta Materialia 53 (2005) 523-527

54. I. Hoffmann, Y.-T. Cheng, D. Puleo, G. Song, R. Waldo, Mg-Ti: A possible biodegradable, biocompatible, mechanically matched material for temporary implants, Mater. Research Symp. Proc., Vol. 1301, 2011, Materials Research Society, DOI:10.1557/opl.2011.566

55. K.A. Unocic, H.H. Elsentriecy, M.P. Brady, H.M. Meyer, G.L. Song, M. Fayek, R.A. Meisner, B. Davis, Transmission Electron Microscopy Study of Aqueous Film Formation and Evolution on Magnesium Alloys, Journal of the Electrochemical Society 161(6) (2014)C302-C311

56. G.-L. Song, K.Unocic, The Anodic Surface Film and Hydrogen Evolution on Mg, Corrosion Science 98 (2015) 758-765

57. G. Song, C-N. Cao, H-C.Lin, The Stability of the Transpassive Film on 304 Stainless Steel with Post-treatment, Corrosion Science 36 (1994)165-169 
58. G. Song, Transpassivation of Fe-Cr-Ni stainless steel, Corrosion Science 47 (2005)19531987

59. G.-L. Song, R. Mishra, Z. Xu, Crystallographic Orientation and Electrochemical Activity of AZ31 Mg Alloy, Electrochemistry Communications 12 (2010)1009-1012

60. G.-L. Song, Z. Xu, Crystal Orientation and electrochemical corrosion of polycrystalline Mg, Corrosion Science 63(2012)100-112

61. L. Zhu, G. Song, Improved corrosion resistance of AZ91D magnesium alloy by an aluminium-alloy coating, Surface and Coatings Technology 200(2006)2834-2840

62. C. Liu, Y. Xin, X. Tian, J. Zhao and P. K. Chu, Corrosion resistance of titanium ion implanted AZ91 magnesium alloy, J. Vac. Sci. Technol. A 25(2007)334-339

63. M. Vilarigues, L.C. Alves, I.D. Nogueira, N. Franco, A.D. Sequeira, R.C. da Silva, Characterisation of corrosion products in $\mathrm{Cr}$ implanted $\mathrm{Mg}$ surfaces, Surface \& Coatings Technology 158 (2002) 328-333. 


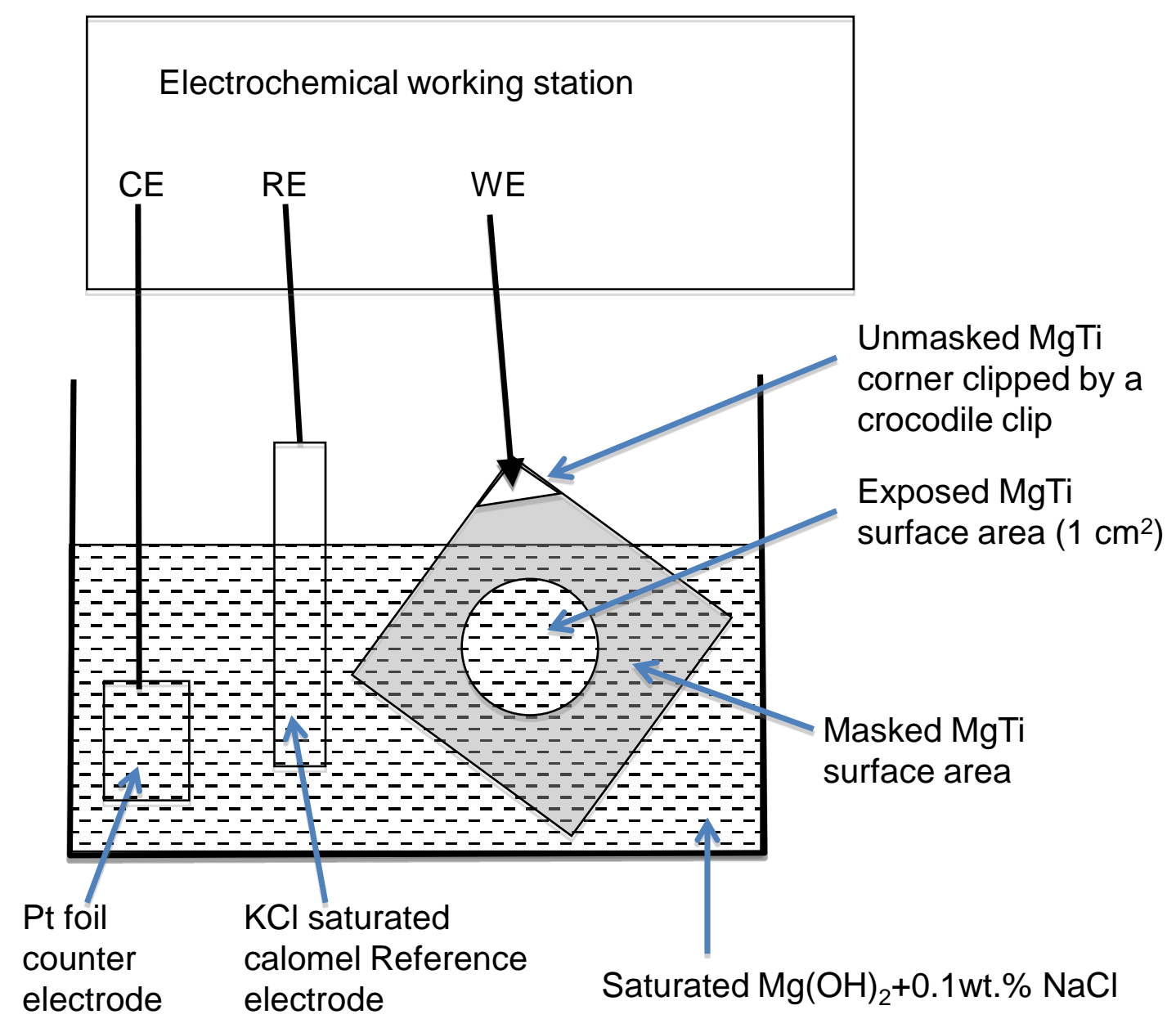

Figure 1. Schematic illustration of the Mg-Ti electrode and electrolyte cell set-up for polarization curve measurement 

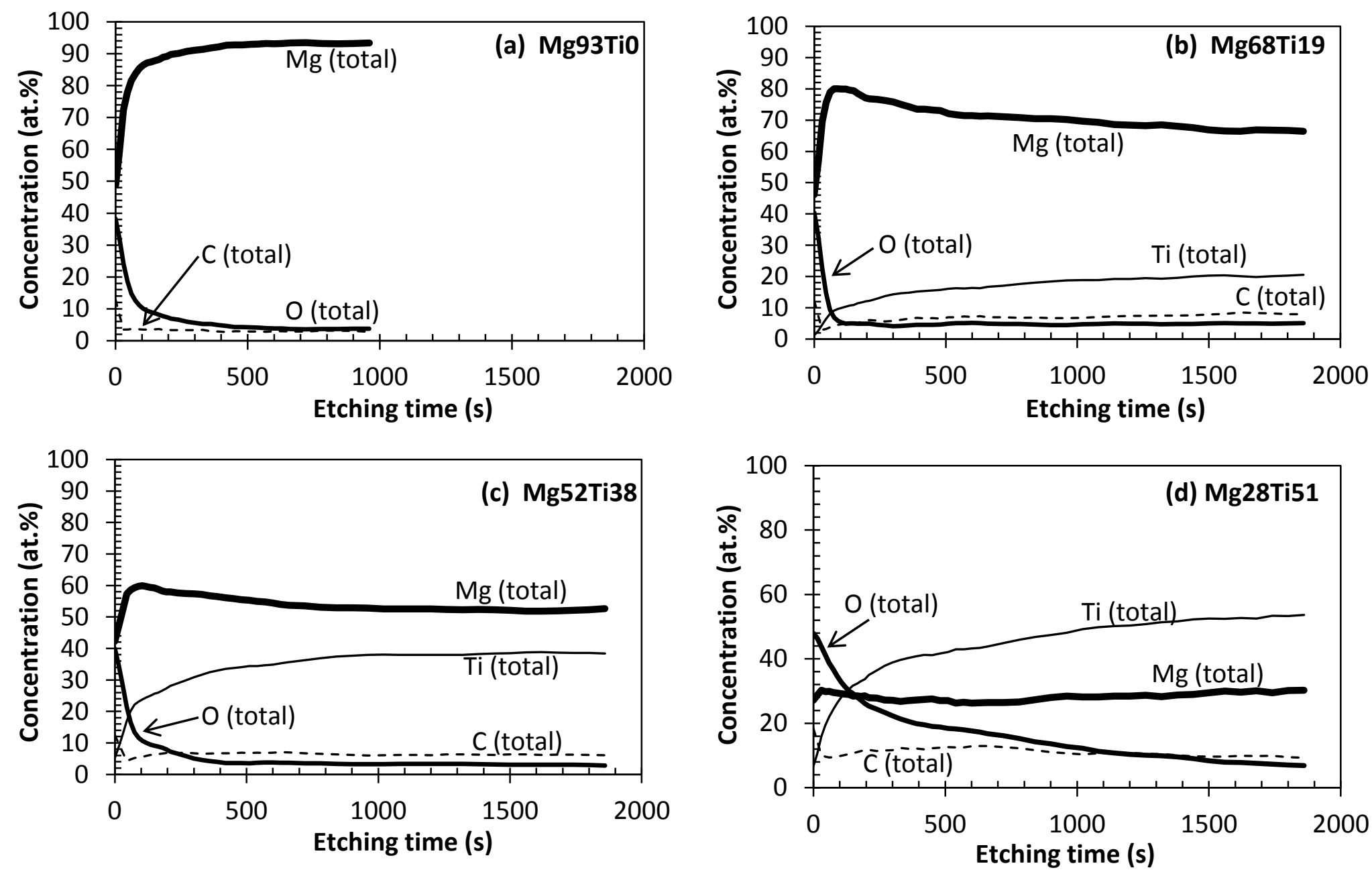

Figure 2. XPS element profiles of magnetron-sputtered Mg-Ti alloys: (a) Mg93Ti0, (b) Mg68Ti19, (c) Mg52Ti38 and (d) Mg28Ti51 


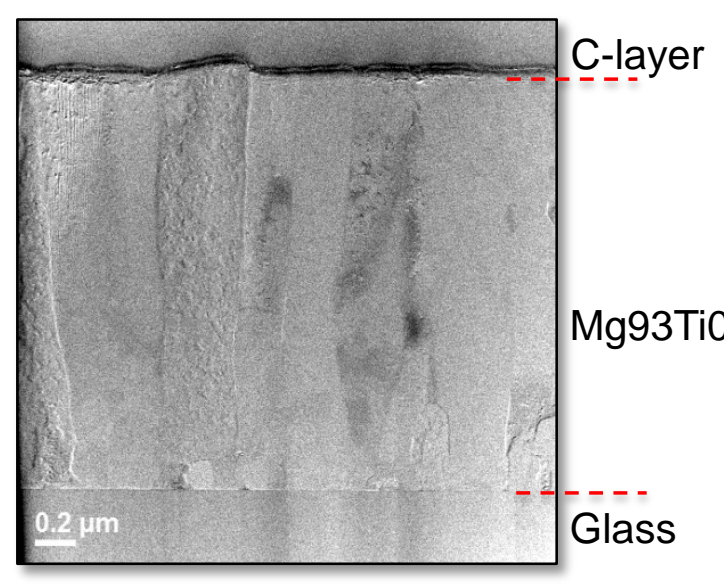

(a) Mg93Ti0

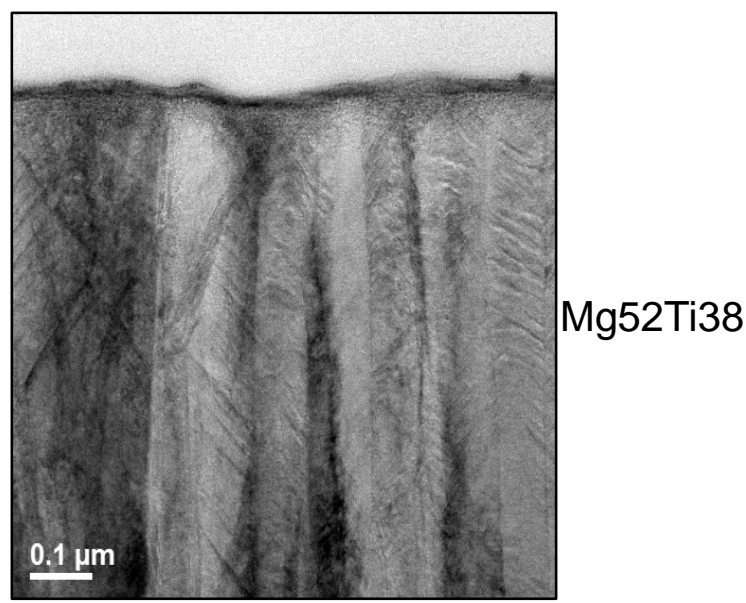

(b) Mg52Ti38

Figure 3. Bright Field STEM images of typical cross-sections of magnetron-sputtered Mg-Ti alloys: (a) Mg93Ti0 and (b) Mg52Ti38 


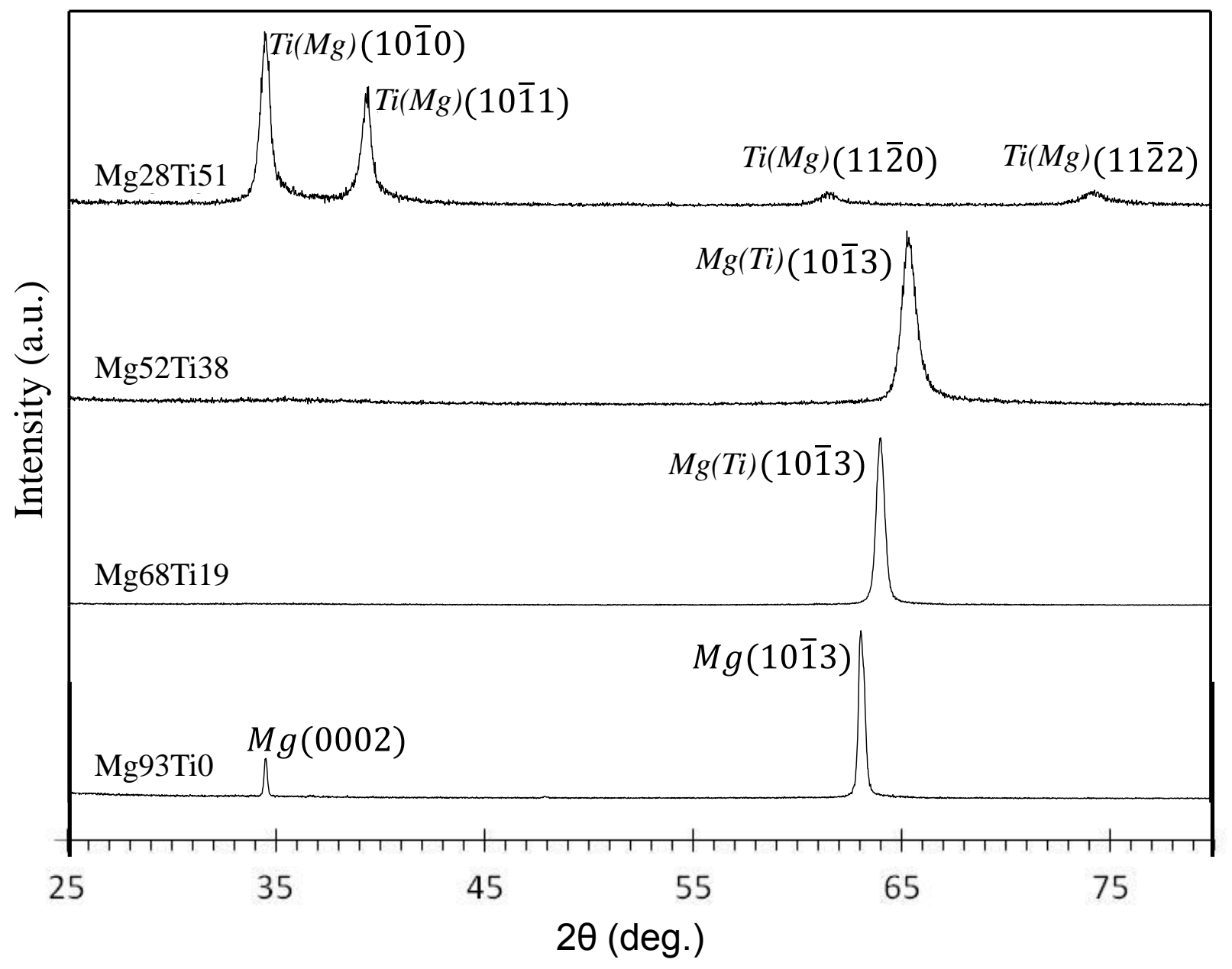

Fig.4. XRD spectra of magnetron sputtered Mg-Ti alloys 


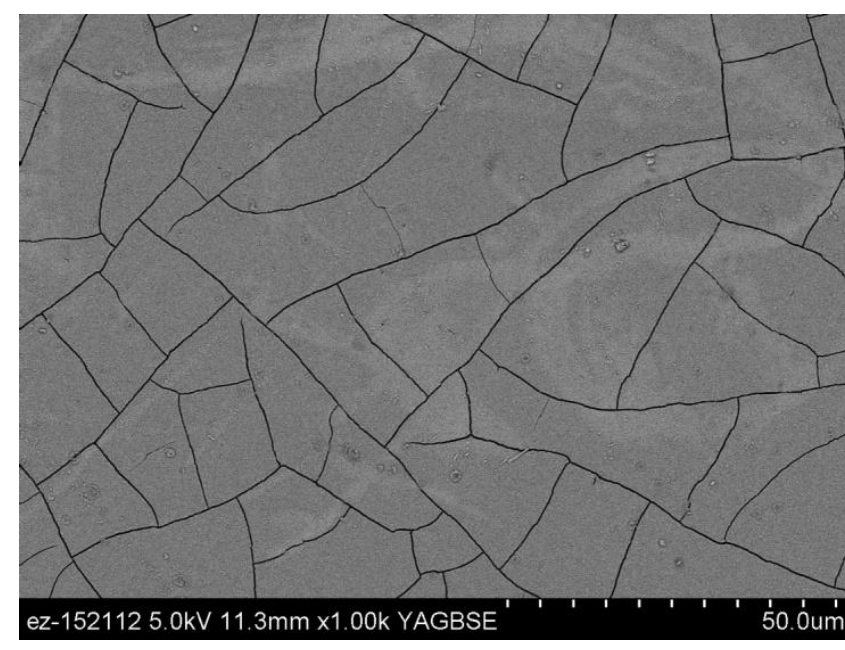

(a) $\mathrm{Mg} 93 \mathrm{Ti0}$

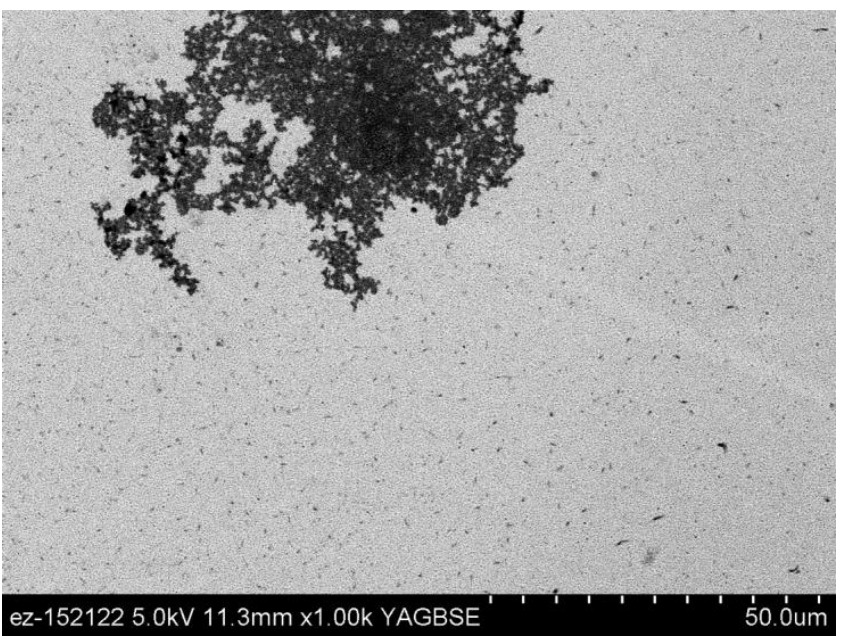

(c) $\mathrm{Mg} 52 \mathrm{Ti} 38$

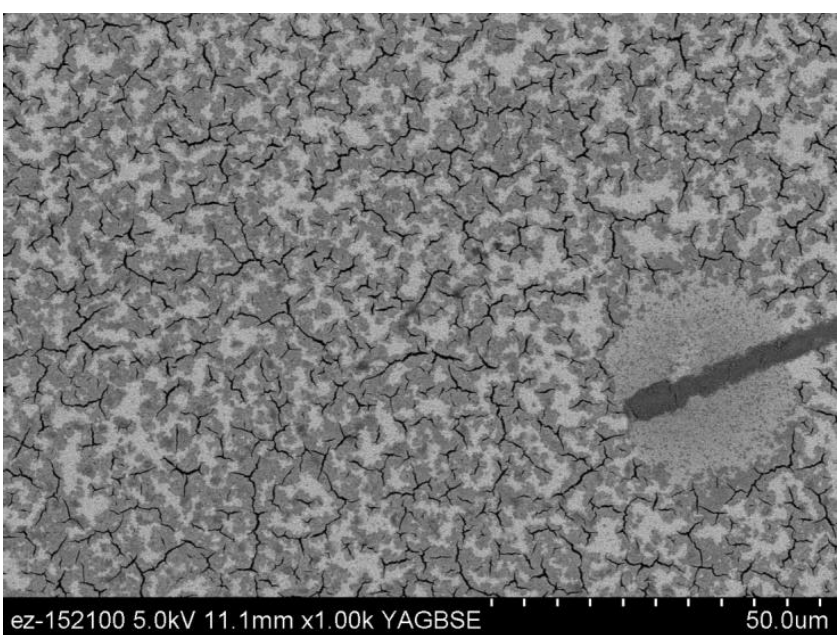

(b) Mg68Ti19

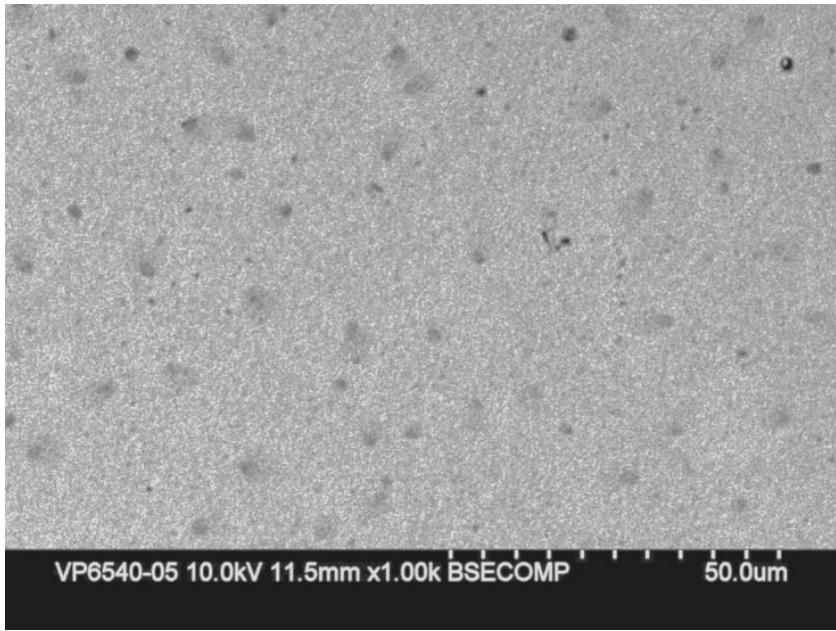

(d) $\operatorname{Mg} 28 \mathrm{Ti} 51$

Figure 5. Backscattered SEM images of the top view of magnetron-sputtered Ti-Mg alloys: (a) Mg93Ti0, (b) Mg68Ti19, (c) Mg52Ti38 and (d) Mg28Ti51, after $5 \mathrm{~h}$ of immersion in saturated $\mathrm{Mg}(\mathrm{OH})_{2}+0.1$ wt. $\% \mathrm{NaCl}$. 

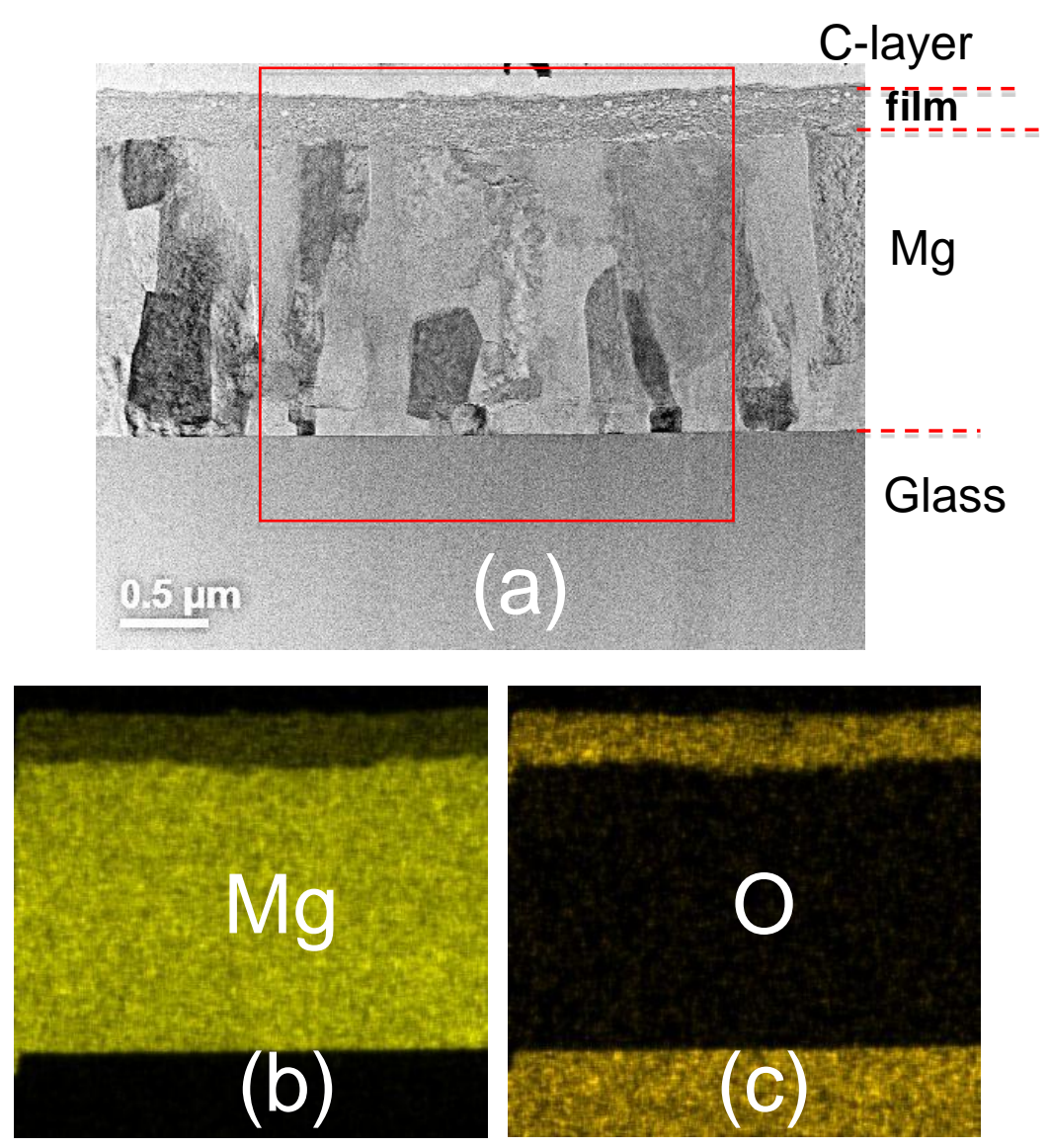

Figure 6. Bright Field STEM image (a) of the cross-section for the magnetron-sputtered MgTi alloy Mg93Ti0 after $5 \mathrm{~h}$ of immersion in saturated $\mathrm{Mg}(\mathrm{OH})_{2}+0.1 \mathrm{wt} . \% \mathrm{NaCl}$, and EDS elemental maps for $\mathrm{Mg}(\mathrm{b})$ and $\mathrm{O}(\mathrm{c})$. 

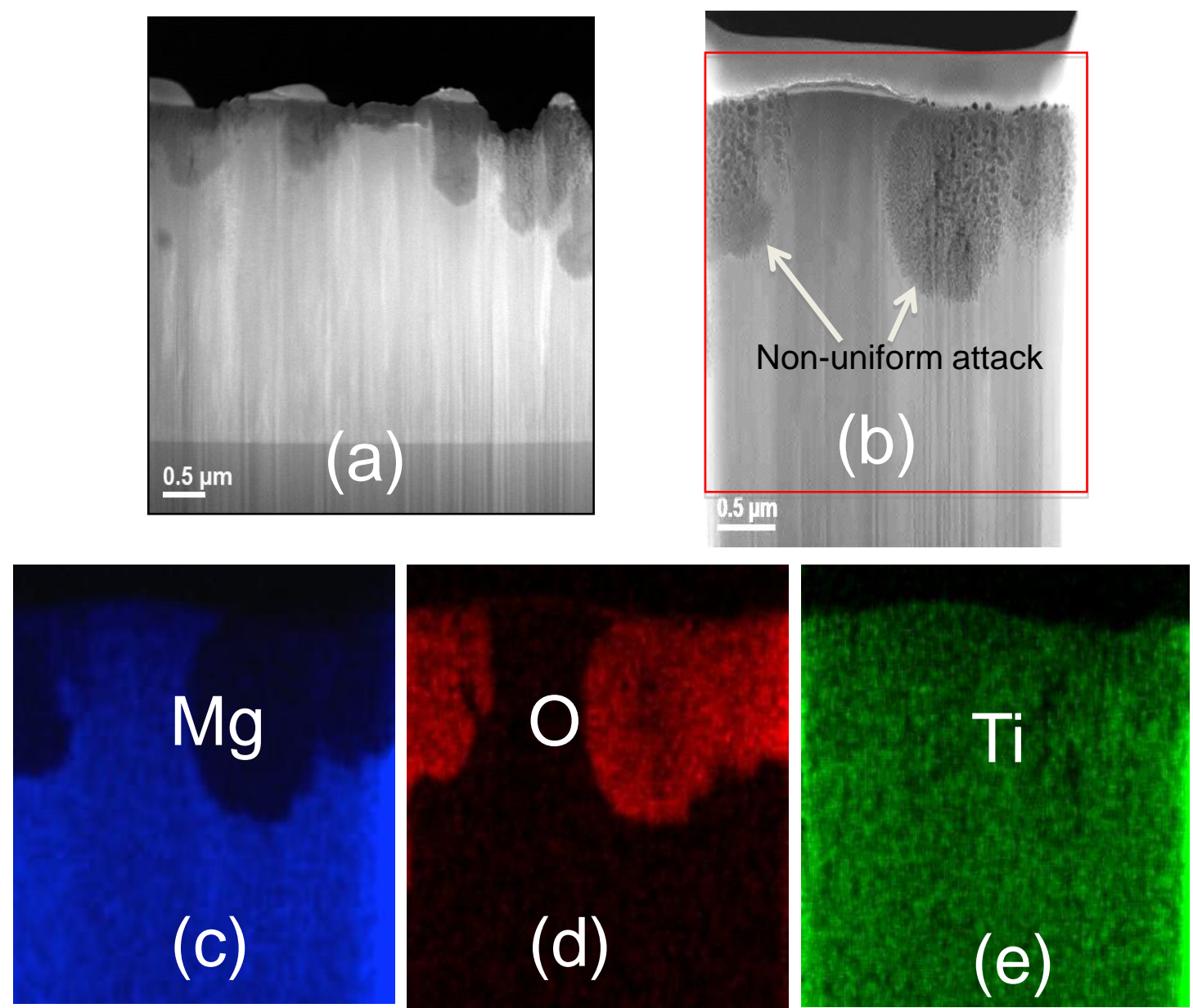

Figure 7. Bright Field STEM images $(\mathrm{a}, \mathrm{b})$ of the cross-section for the magnetron-sputtered Mg68Ti19 alloy after $5 \mathrm{~h}$ of immersion in saturated $\mathrm{Mg}(\mathrm{OH})_{2}+0.1 \mathrm{wt} . \% \mathrm{NaCl}$, and EDS elemental maps for $\mathrm{Mg}(\mathrm{c}), \mathrm{O}(\mathrm{d})$, and $\mathrm{Ti}(\mathrm{e})$. 

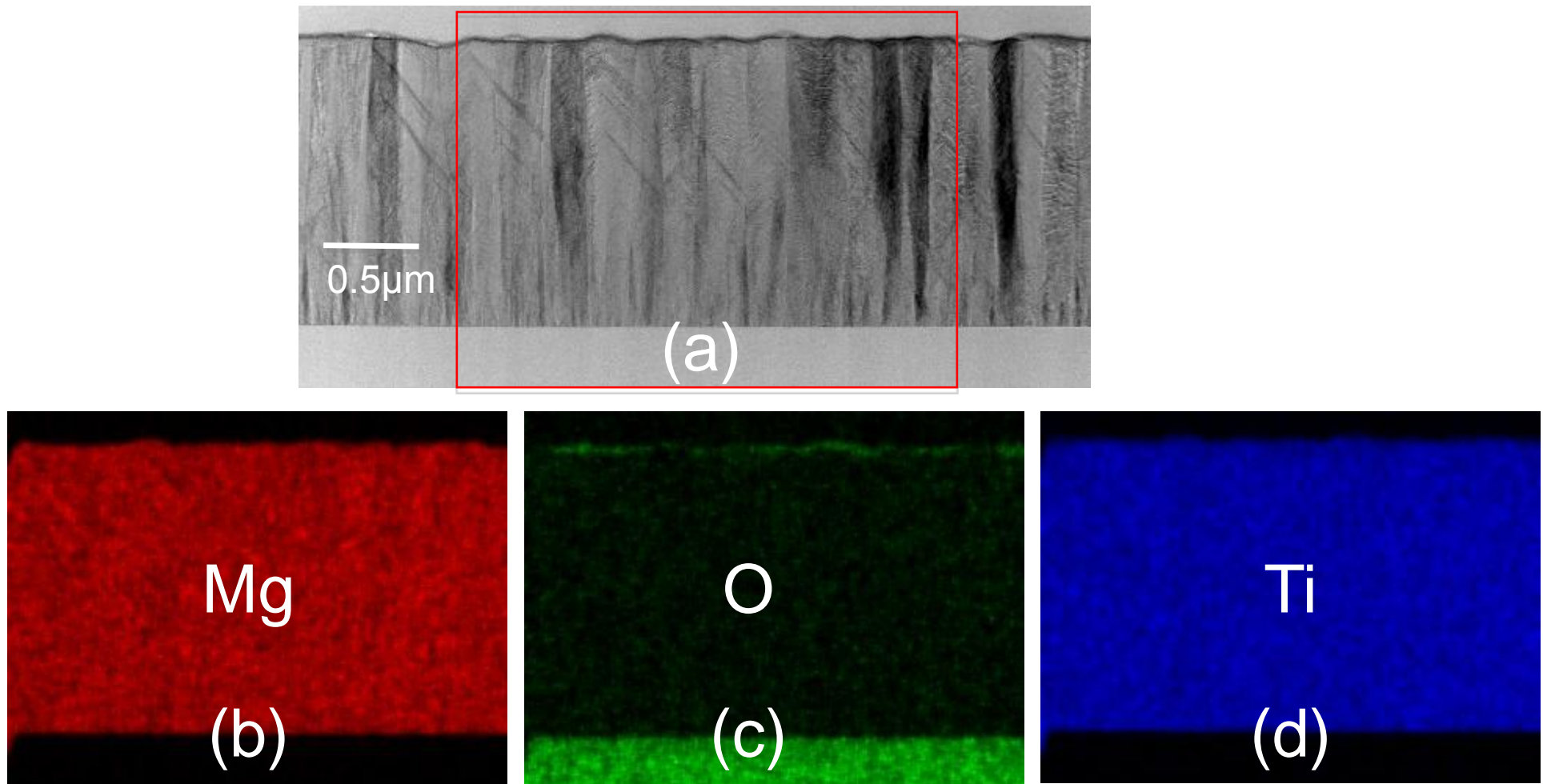

Figure 8. Bright Field STEM image (a) of the cross-section of the magnetron-sputtered Mg-Ti alloy Mg52Ti38 after $5 \mathrm{~h}$ of immersion in saturated $\mathrm{Mg}(\mathrm{OH}) 2+0.1 \mathrm{wt} . \% \mathrm{NaCl}$, and EDS elemental maps for $\mathrm{Mg}(\mathrm{b}), \mathrm{O}(\mathrm{c})$, and $\mathrm{Ti}(\mathrm{d})$. 

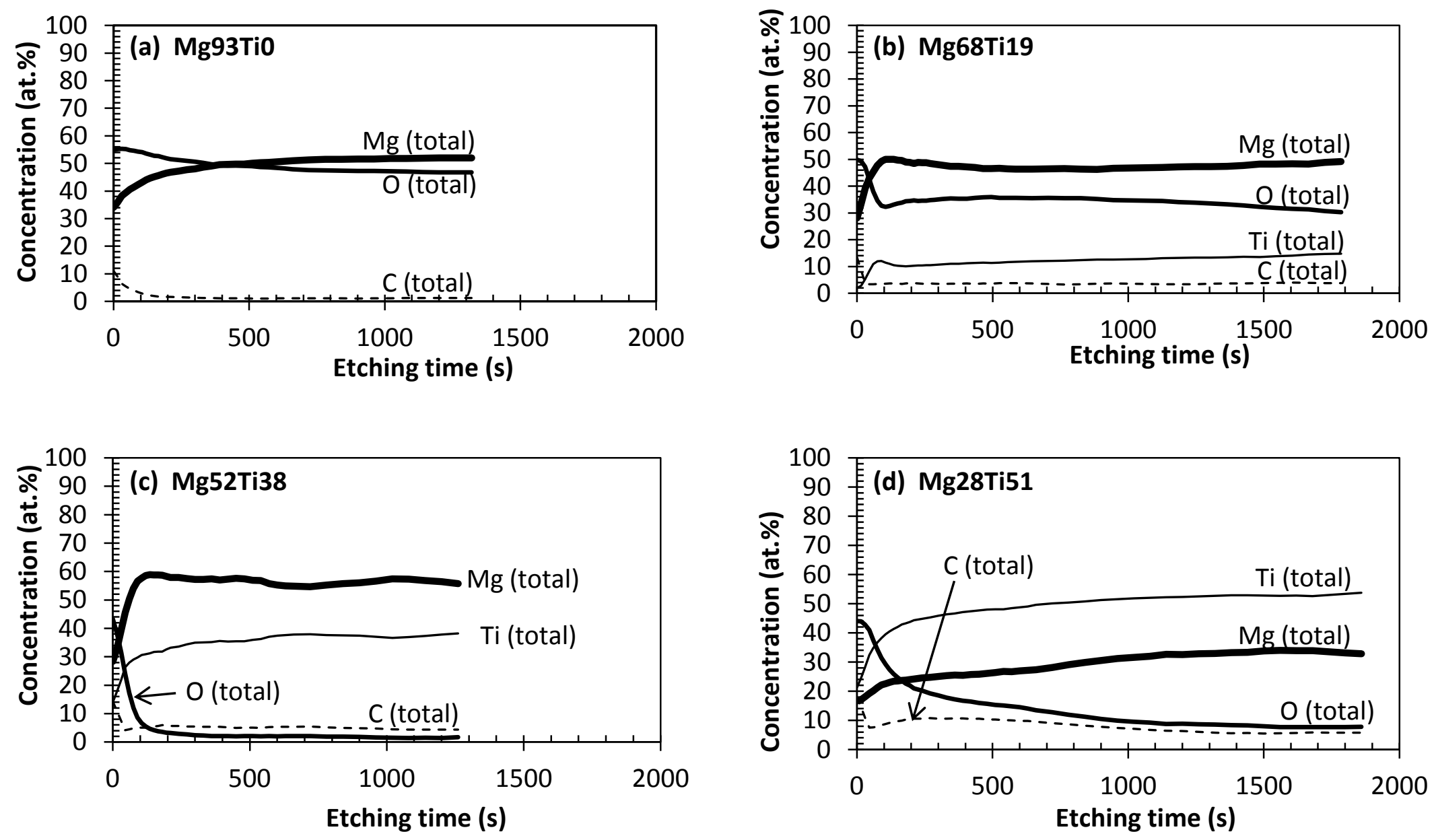

Figure 9. XPS element profiles of Mg-Ti alloys: (a) Mg93Ti0, (b) Mg68Ti19, (c) Mg52Ti38 and (d) Mg28Ti51after $5 \mathrm{~h}$ of immersion in saturated $\mathrm{Mg}(\mathrm{OH})_{2}+0.1$ wt. $\% \mathrm{NaCl}$. 


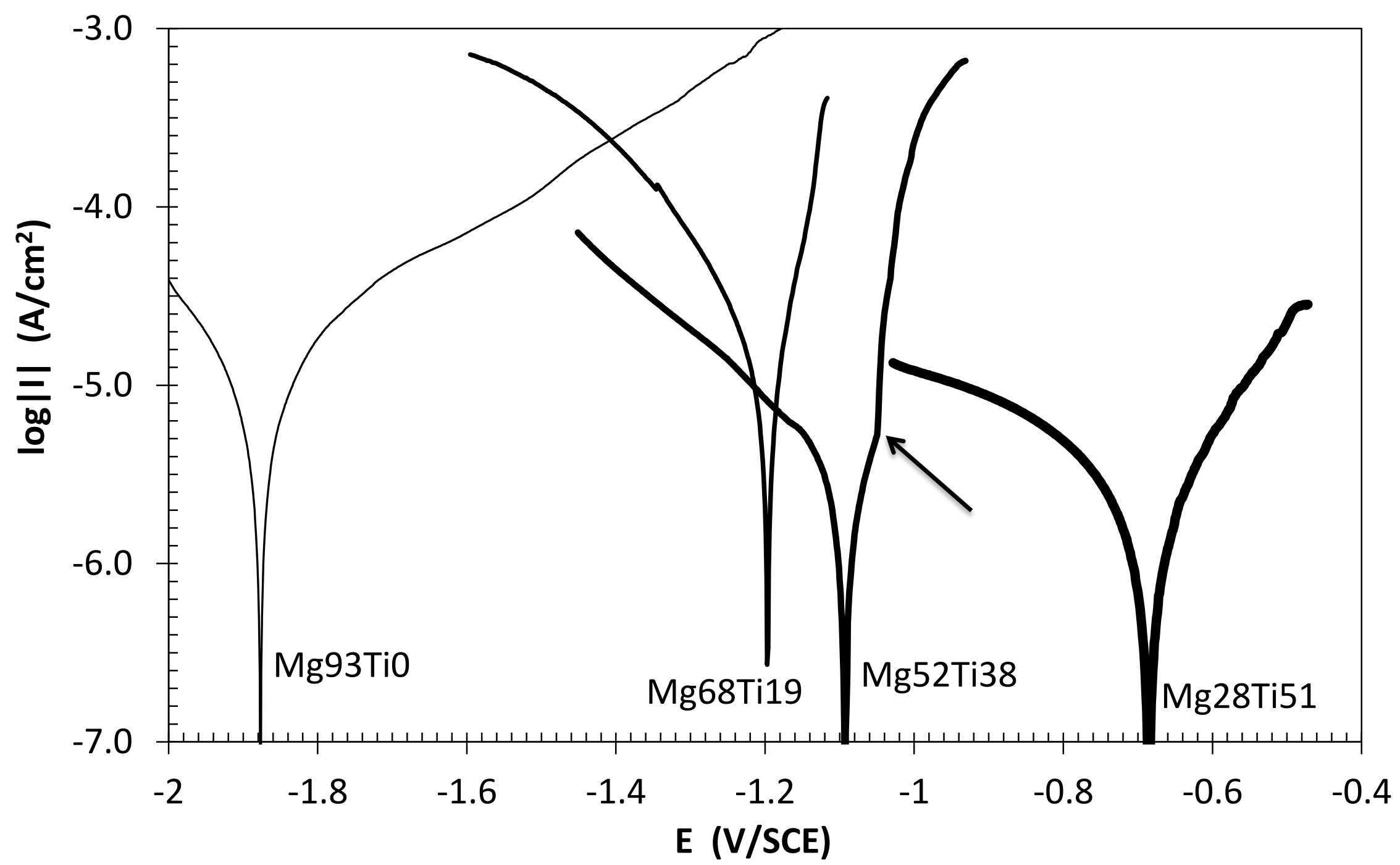

Figure 10. Polarization curves for magnetron-sputtered $\mathrm{Mg}$-Ti alloys on the rotating holder in saturated $\mathrm{Mg}(\mathrm{OH}) 2+0.1 \mathrm{wt} . \% \mathrm{NaCl}$ solution 